\title{
Novel Approaches to Friction Spot Welding Thin Aluminium Automotive Sheet
}

\author{
Philip B Prangnell ${ }^{1, a}$, and Dimitrios Bakavos ${ }^{1, b}$ \\ ${ }^{1}$ Materials Science Centre, School of Materials, The University of Manchester, Grosvenor Street, \\ Manchester, M1 7HS, UK.

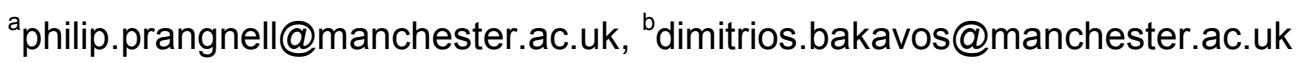

Keywords: Friction stir spot welding; FSSW, Ultrasonic welding; AA6111, Lap shear strength.

\begin{abstract}
Conventional welding methods, like resistance spot welding, are inefficient and difficult to apply to light alloys. Two alternative new solid state friction joining techniques, which have not yet been fully optimized, are high power Ultrasonic Spot and Friction Stir Spot Welding (USW \& FSSW). Here we have compared the performance for these two processes for producing 'keyholeless' welds in thin aluminium automotive closure panels. For friction stir spot welding this was achieved through using a novel 'pinless' tool to create a joint without a retained keyhole and reduce the weld cycle time. The properties of the welds that can be produced by each technique are compared, together with the stages of weld formation, and the relationship between welding conditions and joint performance.
\end{abstract}

\section{Introduction}

There is pressure in the transport sector to move towards lower fuel consumption. This has highlighted the need for more efficient methods for joining light alloys. For example, resistance spot welding (RSW) is difficult to apply to aluminium alloys because of their high conductivity, low strength at temperature, and tendency to degrade the electrodes. Alternative solutions under investigation by the automotive industry include; self piercing rivets, adhesive bonding, and laser and GTA welding. Of these methods, fusion processes are limited by the poor weldability and high levels of distortion that are characteristic of aluminum alloys [1]. Furthermore, riveting has high consumable costs. In comparison, Ultrasonic Spot (USW) and Friction Stir Spot Welding FSSW) [2-7] are two alternative very promising new solid state techniques, that can be directly substituted for RSW, but use less than $10 \%$ of the energy and avoid many of the problems of conventional welding because they do not melt the material. However, neither of these methods have yet been fully optimized and a number of issues remain.

In FSSW a high speed rotating tool, consisting of a shoulder with a probe/pin, is plunged into the upper sheet of a lap joint while an anvil supports the down force [2-5]. The heated material below the tool deforms plastically to high strains, disrupting the oxide at the joint interface, so that a solidstate bond can be formed between the upper and lower sheets. There is now a wide body of research that shows that high quality welds can be made by this technique (e.g. [2]). However, problems remain, including; the undesirable keyhole produced by the tool probe, the difficulty of obtaining a full metallurgical bond and thinning of the top sheet ('hooking') [2-5]. The weld cycle is also longer than ideal for the automotive industry, being typically 2 to 4 seconds [2-4]. The 'refill' technique developed at GKSS, with a two part actuated tool, can solve some of these problems, but makes the equipment more complex and tends to result in a longer weld times [2].

An alternative option is to exploit modern advances in ultrasonic metal welding, a process that has been used since the 1950's to join thin foils [6,7]. Recently, high power systems have become available and in the last few years research by Ford Motor company has shown that USW can be applied to friction spot welding aluminum panels up to $3 \mathrm{~mm}$ thick [8,9]. This technique creates a 
friction weld by inducing a small $(10-50 \mu \mathrm{m})$ high frequency linear displacement across the weld interface. One of the main advantages of USW, relative to FSSW, is that very short weld cycle times can be used (e.g. $<0.5 \mathrm{sec}$ ). However, with the exception of a few publications [8,9], relatively little is currently known about the influence of the welding conditions, the bonding process, or the effect on the parent material. Furthermore, to date no one has attempted to directly compare the two processes.

Here we will first show how the FSSW technique can be modified to make it more suitable for joining thin automotive sheet, by reducing the weld cycle to less than 1 second and eliminating the keyhole, by removing the tool probe, before comparing the joint performance and weld evolution to that of the competing ultrasonic welding process.

\section{Experimental}

All the data presented is for welds produced in $0.91 \mathrm{~mm}$ thick 6111 -T4 aluminium sheet with no cleaning or surface preparation prior to joining. Friction stir spot welding was carried out under displacement control on a CS Powerstir FSW machine using a tool with a $10 \mathrm{~mm}$ diameter shoulder. An optimized minimum shoulder plunge depth of $0.2 \mathrm{~mm}$, plunge rate of $2.5 \mathrm{~mm} / \mathrm{sec}$, and rotational speed of $2000 \mathrm{rpm}$ was used in the studies. The temperature at the base of the weld was recorded by embedding a thermocouple vertically in the anvil. The weld energy was calculated from integrating the torque curve. For USW welding a commercial dual head Sonobond MH2016 ultrasonic welding machine was used, with serrated patterned $6 \times 10 \mathrm{~mm}$ tips, oriented with the long dimension parallel, and the ridges perpendicular, to the vibration direction. Welds were performed under a constant pressure of 5.5 bar, at different weld energies by varying the weld time with a constant target power of $2.5 \mathrm{~kW}$ controlled by the machine. The FSSW tool and the USW tips had maximum foot prints of 78 and $60 \mathrm{~mm}^{2}$, respectively. To evaluate the mechanical strength of the joints, tensile lap shear tests were performed on weld coupons made from $25 \mathrm{~mm}$ by $100 \mathrm{~mm}$ strips with an overlap of $25 \mathrm{~mm}$. Results were averaged over three tests with the peak load measured, as well as the total failure energy. The welded joints were sectioned to characterise the weld formation and weld zone microstructure using an FEI Sirion FEG-SEM equipped with a backscattered electron detector and EBSD system. Weld cycles are defined as the time over which energy is applied to the work piece.

\section{Results and Discussion}

Pinless FSSW. Recent results (Fig. 1) have shown that in thin Al sheet $(\sim 1 \mathrm{~mm})$ it is possible to produce higher strength and fracture energy welds in FSSW with either a much shorter probe than conventionally used, or no probe at all [5]. In thin sheet, when the deformation zone from the shoulder penetrates sufficiently into the bottom sheet (Fig. 1d), a pinless tool appears to give excellent results because it contacts more uniformly across the tool surface, giving a greater chance of bonding under the shoulder at the edge of the weld. This leads to failure by nugget pull out around the periphery of the shoulder contact area, rather than bond line cleavage, leading to stronger welds with a higher fracture energy (Fig. 1b). In Fig. 1a it can be seen that if either a steel or ceramic anvil is used (to reduce heat loss at the bottom face) welds can be produced which are as strong as with an optimum probe length. The optimum probe length itself is $\sim 1 \mathrm{~mm}$, which is shorter than the $1.4 \mathrm{~mm}$ probe tool used by most groups $[3,4]$. The weld quality was found to be excellent, with a metallurgical bonded area of around $60-70 \%$ of the tool foot print for the pinless tool, compared to $20-30 \%$ for a standard $1.4 \mathrm{~mm}$ long probe tool [5]. The possibility of producing high quality welds with a pinless tool in FSSW is counter intuitive, but has many advantages, including a simpler process and a better aesthetic appearance with no retained keyhole.

However, in this work a standard weld time of $2.5 \mathrm{sec}$. was employed, which is longer than ideal for the automotive production. In Fig. 1(c) it can be seen from the area under the torque curves that, there is a greater initial rise in energy for the pinless tool due to the more abrupt touch down across 
the whole shoulder. The pinless tool also results in a shorter plunge time, thus allowing more potential for reducing the weld cycle.
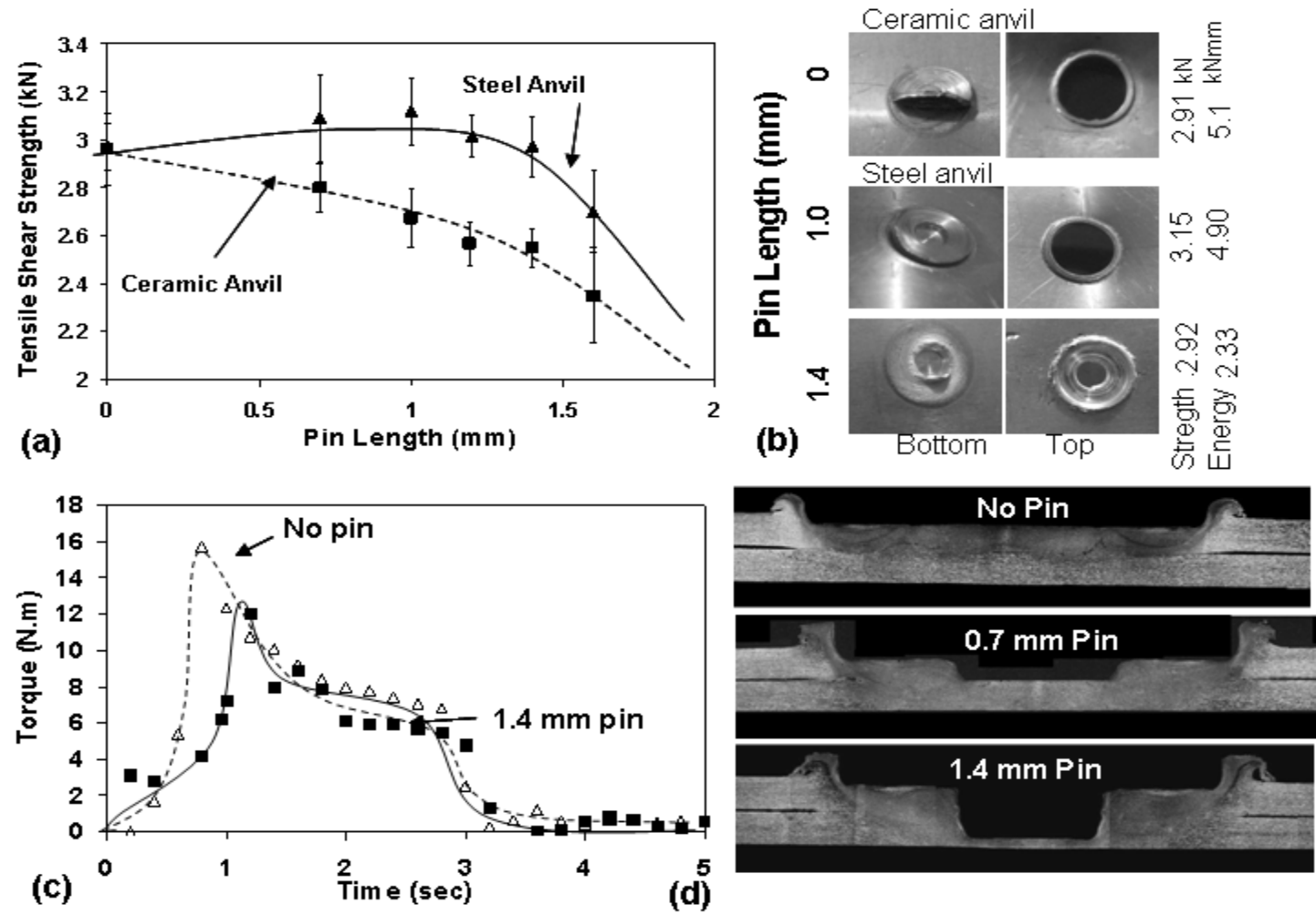

(d)

Fig.1. The effect of reducing the probe length on FSSW thin sheet welding; (a) weld shear strength vs. pin length, with a steel or insulating ceramic anvil (from [5]), (b) top and bottom sheet fracture surfaces, showing nugget pull out, for no pin and a shortened probe and interface debonding with a standard $1.4 \mathrm{~mm}$ pin, including the corresponding shear strengths and failure energies, (c) FSSW torque curves for a pinless tool and with a $1.4 \mathrm{~mm}$ probe (steel anvil) and (d) macroscopic weld cross sections, all for a $2.5 \mathrm{sec}$ dwell time.

Comparison of USW and Pinless - FSSW weld performance. Fig. 2a shows the effect of weld cycle time on weld performance for the two processes. It should be noted that direct comparisons are not straight forward as the two welds have different geometries, with the USW and FSSWs having rectangular and circular footprints, respectively, and the USW has a slightly smaller area. In addition, the optimum set up is different for each process. For USW the welding power supply tries to maintain a constant target welding power, which was set at $2.5 \mathrm{~kW}$, with a constant applied pressure, whereas in FSSW the plunge was kept constant and the power varies through the weld cycle, with the peak power being delivered when the tool first touches down (see Fig. 1c). For example in FSSW it took $\sim 1 \mathrm{sec}$. to obtain a weld energy of $\sim 1 \mathrm{~kJ}$, but $2.5 \mathrm{sec}$. for $\sim 3 \mathrm{~kJ}$. In Fig. 1 (a), the lap shear strength results show clearly different characteristic curves with weld time for the two welding techniques. For FSSW, plunging the pinless tool to the desired depth $(0.2 \mathrm{~mm})$ and immediately withdrawing with no dwell, gave the shortest possible weld cycle of only 0.4 sec. Surprisingly, it can be seen that this resulted in welds with the highest shear strength, equal to 3.5 $\mathrm{kN}$. This strength level is extremely favorable compared to other results reported in the literature in the same material, which used a conventional $\sim 1.4 \mathrm{~mm}$ long pin tool and range up to $3 \mathrm{kN}$ [4]. However, while the weld strength decreases progressively with weld time, the fracture energy increases slightly up to an optimum at $\sim 1 \mathrm{sec}$. before also decreasing for longer times.

In the case of the USWs the optimum weld time is only $0.25 \mathrm{sec}$, equivalent to $630 \mathrm{~J}$, where the weld exhibits both the highest shear strength and failure energy. The maximum lap shear strength is similar to that of the optimum time pinless-FSSW, being $\sim 3 \mathrm{kN}$, but the peak failure energy is higher $(7.3 \mathrm{kNmm}$ compared to $5.3 \mathrm{kNmm})$. Similar optimum USW strengths have been reported by Jhan et. al. [8] with the same material. Overall, it can be seen that pinless-FSSW is a much more robust process, as the mechanical test results show a far lower sensitivity to the welding parameters. 
The top and bottom sheet surfaces of selected fractured samples are shown in Fig. 2b, where it can be seen that for both welding techniques there is a change in shear failure mode with weld time. For short weld times the weld interface debonds, and as the weld time and energy increases, the failure mode changes to favor nugget pullout, by tearing around the periphery of the welded area. However, too long a weld time reduces the weld failure energy. In the case of the USW, this is due to excessive thinning when the temperature gets too high, caused by the welds being produced under pressure control (see Fig. 4 below). In comparison, with FSSW, longer weld times result in partial debonding with the fracture path tearing through to the top sheet leaving a reduced diameter attached nugget. The progressive loss of shear strength with weld time for the FSSWs is probably related to a general loss of material strength due to overageing from the higher heat input.
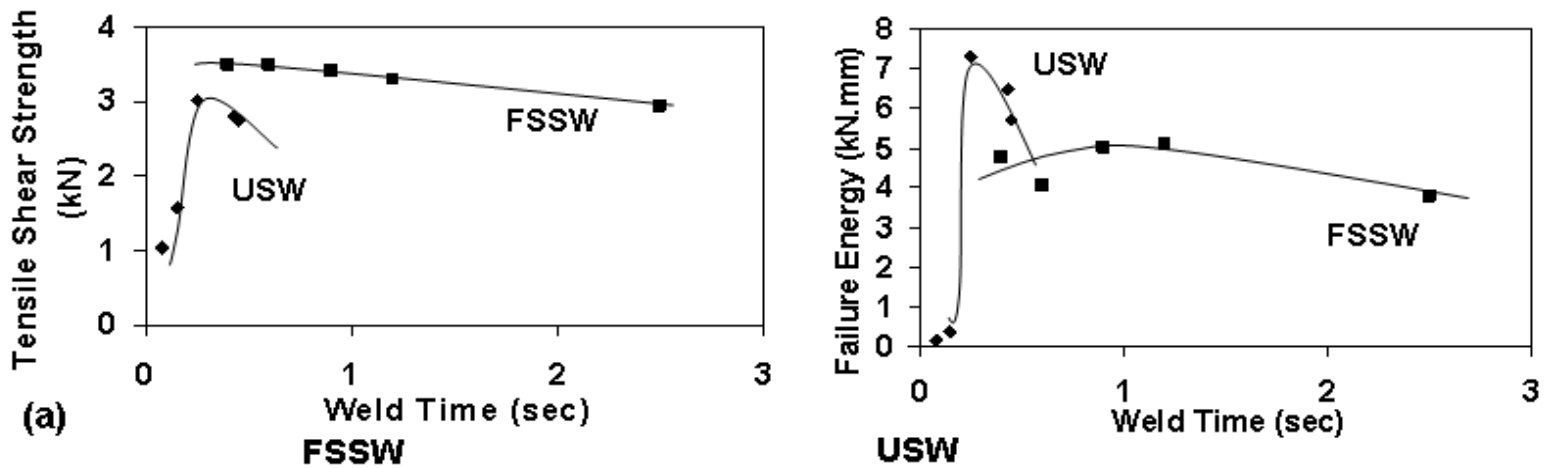

(b)

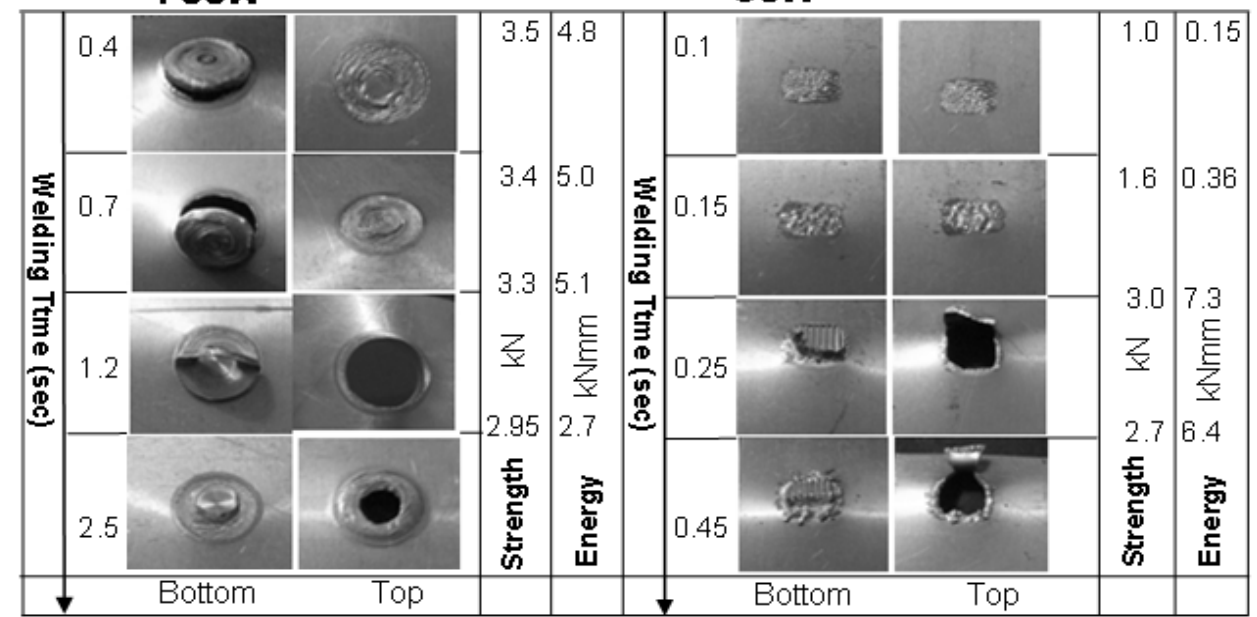

Fig. 2. Comparison of the effect of weld time on; (a) shear strength and failure energy, and (b) the failure mode, for the USW and pinless, friction stir spot welds.

Weld Formation. In Fig. 3 optical images are shown of sections through welds, produced as a function of time, to illustrate the sequence of weld development. In the FSSWs it can be seen that a doughnut shaped weld deformation zone develops first under the edge of the tool, where the radial velocity is greatest and there will be the most rapid heat generation if the tool couples well with the sheet surface. In the very short zero dwell time, weld there is insufficient deformation to create a bond in the centre of the weld. However, as strong bond is still produced under the edge of the tool, where interface rupture typically occurs when a pin tool is used. As the weld dwell cycle time increases, the deformation zone expands mainly inwards, disrupting the join line towards the weld centre. However, this appears to occur in zones, with distinct secondary inner doughnut rings being subsequently produced, which results in a wavy join line. This behaviour can be attributed to a slip condition forming under the edge of the tool as the material gets too hot, which transfers the deformation inwards when the material becomes soft enough, as the temperature rises, to continue to flow under sticking conditions. Overall, it can be seen that the deformation zone extends down about $1 \mathrm{~mm}$ which, with a $0.2 \mathrm{~mm}$ plunge, penetrates the bottom sheet enough to allow the severe deformation to stretch out the original surface oxide skin sufficiently on the bottom sheet to expose atomically clean new surface and allow a metallurgical bond to form. EBSD analysis (Fig. 3c) reveals that the severe deformation leads to an extremely fine grain structure within the weld deformation zone of $\sim 1-3 \mu \mathrm{m}$. 


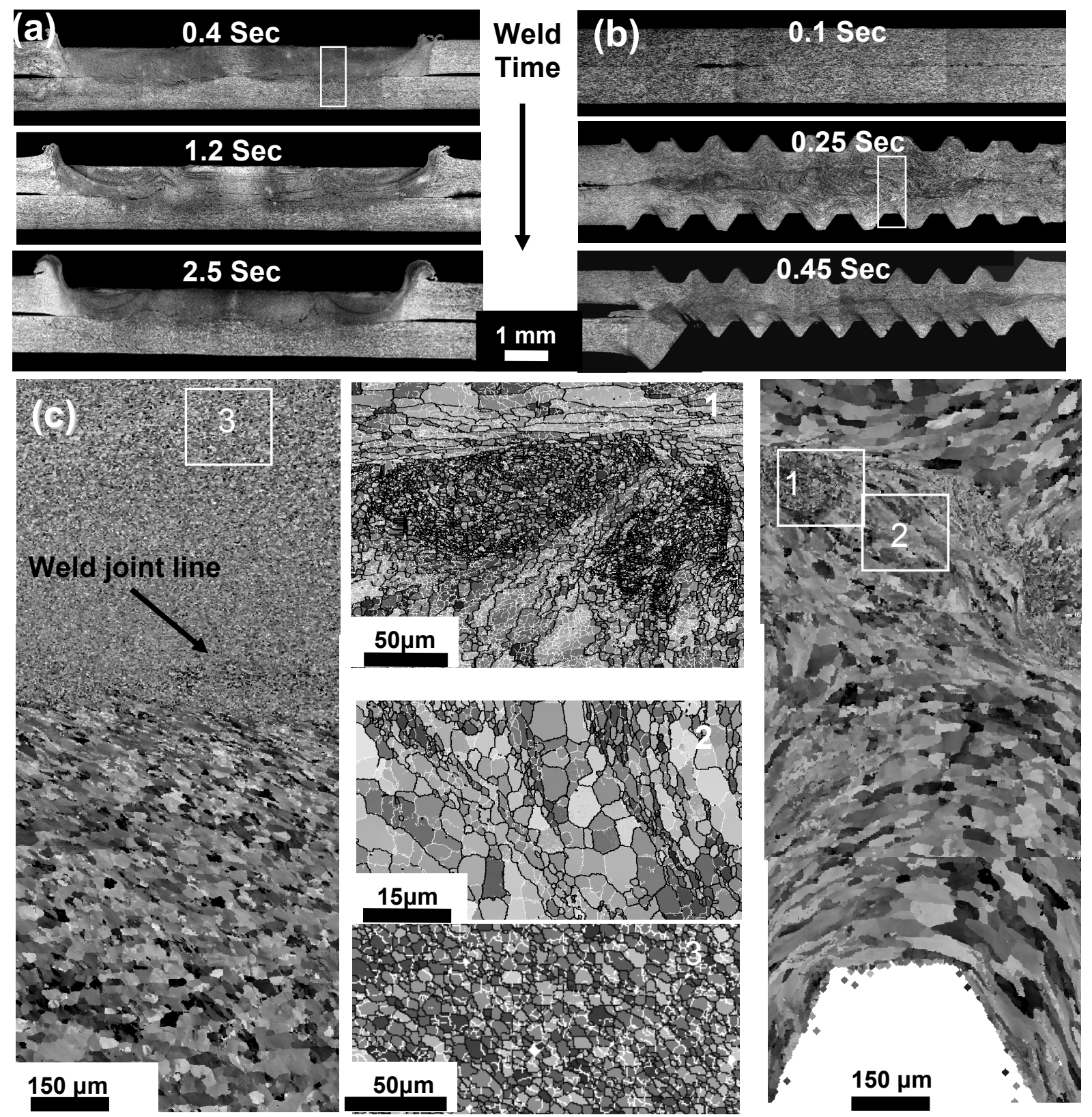

Fig. 3. Weld formation in FSSW and USW; macroscopic sections showing the progressive stages of weld development for (a) FSSW, and (b) USW, and EBSD analysis of the grain structures within the deformation zones, (c) FSSW for the $0.4 \mathrm{sec}$ weld and (b) USW from a $0.25 \mathrm{Sec}$ weld. The magnified EBSD maps are the 3 numbered regions highlighted.

In the ultrasonic welds it can be seen that the effect of weld time is more critical (Fig. 3b). Research in the 70's, into lower power USW metal welding, has shown that weld formation occurs by the development and spread of microwelds [7]. Initially sliding friction occurs with contact between asperities on the sheet surfaces. The area of contact thus increases with the applied pressure and when the material flow stresses reduces as the interface temperature rises. As the temperature increases at the interface, the oxide becomes damaged and galling occurs, leading to the formation of elliptical microwelds, which are elongated in the direction of oscillation. There is then a more rapid increase in temperature, due to the rise in plastic work, and a growth in the density of microwelds, which also expand and start to merge. A high density of microwelds first form under the edge of the tool, with bonding in the centre occurring more slowly and initiating under the tool ridges where the local pressure is highest. There is thus a threshold weld energy, or time, below which little bonding occurs, which for this sheet thickness was $\sim 200 \mathrm{~J}$. However, if too much weld energy is used the material becomes too soft and metal is squeezed out, leading to a lower quality weld. In the EBSD analysis it can be seen that there are a number of interesting features in high 
power USWs, which have not been previously reported in detail [8]. There are three zones apparent in the weld: i) close to the interface where severe deformation occurs and wavelets are formed with an extremely fine (1-2 $\mu \mathrm{m})$ grain structure (' 1 ' in Fig. $3 \mathrm{~d})$; ii) a shear zone which develops towards the end of welding when adhesion has occurred, with shear bands at $\sim 45^{\circ}$ extending up to the tool surface and connecting with the troughs caused by the ridged tool (Fig. $3 \mathrm{~b}$ and ' 2 ' in Fig. d); and iii) a forged zone, where the surfaces of the sheet have largely been deformed in compression, and the serrated tool surface is forced into the material when it softens as the temperature rises (Fig. 3d). The wavelets at the interface result in a very convoluted join line. How they form is not currently well understood [8], but it is likely that they develop as a result of the oscillatory nature of the shear strain and the progressive development of microwelds. Regions that bond early on, such as under the edge of the tool tip, or beneath the tool ridges, will generate ligaments that are stretched out by the shear strain. However, this is not a fully reversible process, as once new surface is created it will not to be so easily destroyed and will fold back in when the direction of shear is reversed. It is thus likely that the wavelets form from a 'ratcheting' effect, due to the cyclic nature of the shear strain.

\section{Conclusions}

High power ultrasonic spot and pinless-friction stir spot welding are two very energy efficient, promising, alternative solid state joining techniques, for welding thin aluminium sheet closure panels in automotive applications. With friction stir spot welding it has been shown that high quality welds, with no keyhole, can be produced using a novel 'pinless' tool and far shorter weld cycles than previously thought. High strength welds could be produced in less than 0.5 of a second, with no dwell time. The optimum weld time for USW is also extremely short, being $\sim 0.25 \mathrm{sec}$. The properties of the welds formed by both processes are very good with shear strengths over $3 \mathrm{kN}$ recorded. In both processes weld formation occurs in stages. In FSSW the deformation zone first develops as a doughnut ring under the edge of the tool and in USSW, weld formation involves the spread of microwelds at the interface, initiating at the edge of the tool tip and under the tool serrations. In FSSW there is a strain gradient decreasing from the tool surface, which results in an approximately bowl shaped ultrafine grained nugget zone. In contrast, USW gives rise to three distinct zones, with a severely deformed interface layer, containing wavelets, a shear zone and a surface forged zone.

\section{Acknowledgements}

The authors would like to thank Nick Wright and Mike Shergold for very helpful technical discussions, D. Tsivoulas for the EBSD analysis and LATEST, the University of Manchester EPSRC Light alloys Portfolio Partnership (EP/D029201/1), for funding this research.

\section{References}

[1] T.A. Barnes and I.R. Pashby: J. Mat. Proc Tech. 99 (2000), p. 62.

[2] B. Harsha, F. Hunt, K. Okamoto: Friction Stir Welding and Processing, edited by R.S. Mishra, M.W. Mahoney: ASM (2007), p. 235-272.

[3] A. Gerlich, P. Su, and T.H. North: Metall. Mater. Trans. 37A (2006), p. 2773.

[4] D. Mitlin V. Radmilovic, T. Pan, J. Chen, Z. Feng, and M.L. Santella: Mat. Sci. and Eng. A, 441 (2006), p. 79.

[5] D. Bakavos and P.B. Prangnell: Sci Technol Weld Joining; (2009); in press.

[6] H.P.C. Ganiels: Ultrasonics (1965) p. 190.

[7] J.L Harthoorn: Ultrasonic Metal Welding, Doc. Thesis, Tech. Hogeschool, Eindhoven, (1978).

[8] R. Jahn, R. Cooper and D. Wilkosz: Metall Mater Trans. 38A (2007), p. 570.

[9] N. W. Wright, J. D. Robson, and P.B. Prangnell, SAE Int, (2009); in press. 